\title{
Passenger and Luggage Weight Monitoring System for Public Transport based on Sensing Technology: A Case of Zambia
}

\author{
Apolinalious Bwalya ${ }^{1}$, Jackson Phiri ${ }^{2}$, Monica M. Kalumbilo ${ }^{3}$, David Zulu ${ }^{4}$ \\ School of Natural Science, Department of Computer Science, The University of Zambia
}

\begin{abstract}
The prevalence of overloading, which is exceeding the maximum load weight, on public buses in Zambia is very rampant because there is currently no system to measure and monitor load weight at bus stations, apart from weighbridges on few selected roads located far away from the loading points. The aim of this study was to design and develop a passenger and luggage weight monitoring system to mitigate the challenge of overloading on public buses. To achieve this, a baseline study was conducted to appreciate the challenges of the current system being used to manage passenger and luggage, i.e., load weight, on public buses. The risk factors considered to contribute to compromised road safety leading to road traffic accidents were also established from all stakeholders as follows: 54 percent human, 39 percent road/environmental, 6 percent vehicle and 1 percent was attributed to other factors. The results were then used as a basis to design and develop a load weight monitoring system (LWMS) based on sensing and other emerging technologies like Load Cells, Wireless Sensor Network (WSN), Internet of Things (IoT), and Cloud Computing concepts to automate the measurement of the load weight, capture and transmit data.
\end{abstract}

Keywords-Overloading; load weight; load cells; emerging technologies

\section{INTRODUCTION}

The use of emerging technologies in today's world has greatly improved the way of life, including application in industry and business enterprises to improve organization and business processes. A business process is defined as "a set of logically related tasks and behaviours that organizations develop over time to produce specific business results and the unique manner in which these activities are organized and coordinated" [1]. The Public Transport Sector has also embraced the new era of emerging technologies such as the Wireless Sensor Network (WSN), Internet of Things (IoT), Digital Communication, Cloud Computing, Motion and Weight Sensing, and "big data" analysis [2] which has created a new global potential for less costly "Intelligent Transport Systems (ITS)" to improve road safety and more efficiently manage transport assets.

In 1992 the public transport sector in Zambia was liberalized from state owned to private ownership. This resulted in sharp rise in the number of bus operators and buses. The current public transport sector is largely unregulated though the government through local authorities and various agencies regulate, enforce and superintendent over bus stations, bus registration and licensing, transport fares, road safety, and axial load control, among others [3].

At bus stations, the loading points, the current system of loading passengers and luggage on public buses is not well defined and is chaotic. The bus crews have no system or means to establish how much load weight is to be loaded on the bus within the prescribed maximum load weight limits. The only point where the bus weight is measured is at designated weighbridges on few selected roads way off from the loading point. This challenge leads to overloading which in turn leads to compromised road safety, damage to road pavements, damage to vehicle, higher fuel consumption and so on. Since the load weight loaded on the buses is not measured, the bus owners or operators also do not have any means to obtain detailed accurate data on how much load weight is carried on their buses, apart from relying on number of passenger tickets to calculate expected income and apparently very little or no income from luggage.

Vehicle overloading is a phenomenon resulting from either exceeding the permissible Maximum Axle Load or the Maximum Gross Vehicle Mass (GVM) [4]. Axle load is defined as the weight transmitted onto the road by an axle bearing two tyres or more, while GVM is defined as the net weight of a motor vehicle or trailer together with such weight of goods or passengers or both. The maximum permissible load limits take into account the road design capacity and vehicle tyre ratings among other things [5]. Vehicle overloading results in rapid deterioration of the road pavement infrastructure, leading to high road maintenance costs [6]. A study conducted by the International Road Dynamics Inc., found that 10 percent increase in weight can accelerate pavement damage by over 40 percent [7]. Therefore, the damage caused by overloading rises exponentially with each additional ton of axle load, and this reduces the life of a road substantially. Despite several regulations to deter overloading, enforcement is lacking mainly due to no specific policy and no mechanism of establishing load weight loaded on the buses exist at the moment [7].

The Metrology Act for Zambia Metrology Agency in reference to the National Measurement Units states that "a person shall not, without reference to the standard unit of measurement, in relation to any goods and services quote a price or charge; issue or exhibit a price list, invoice or other document; state a quantity in an advertisement, poster or document; or indicate the net quantity of a commodity on a 
package"[8]. Alas, at the bus stations, the bus crew load the luggage on the bus and even prescribe charges without any reference to any standard unit of measurement.

The rest of this paper is divided into following sections: Section II comprehensively deals with literature review and related works; Section III discusses the methodology that cover: scope of study, specification of developed system, hardware, system flowcharts and prototype design. Section IV highlights the research results; Section V discusses the result; and Section VI gives the research conclusion and future works.

\section{LITERATURE REVIEW}

\section{A. Introduction}

The Roads and Road Traffic Act of Zambia provides guidelines on the prescribed load weight limits for public vehicles [9]. The scientific word for how much an object weighs on a scale is "mass". The words "weight" and "mass" are often used interchangeably, because both are used in everyday language. In many contexts, scales are used to measure weight or mass of an object [10].

Different types of scales are available and can basically be classified as Analog or Digital scale, the latter is of interest for our study. A Digital scale is a scale that has electronic devices on it like digital and LCD screens while an Analog scale is one with mechanical moving parts. A Load Cell is principal component of the Digital or Electronic scale. Accuracy is one of the most important parameter of any scale while calibration is the process of adjusting the scale for accuracy. Factors that can affect the system's weighing accuracy are Load Cell Accuracy, Load Factors, Environmental Forces, Interference with Signal Transmission, and Instrumentation and Control [10].

The use of technology and proliferation of computers and internet has brought enormous changes in the way organizations conduct business. Not only in the business world but also the education sector where the application of ICTs has brought about huge improvements in the education processes like in administration, assessment and management of various stages in education. The application of ICT in business and social life has opened up new possibilities for running and managing organizations as noted by [11]. With the rapid development of processing and storage technologies and success of the internet, computing resources have become cheaper, more powerful and more available than ever before. This technological trend has enabled the realization of a new computing model called cloud computing, in which resources are provided as general utilities that can be leased and released by users through the internet in an on-demand style [12]. The Education sector has also taken advantage of these technological developments so as to improve the management of processes especially in the area of learning, assessment and candidate registration.

\section{B. ICTs in Public Transport Systems}

Transportation is rapidly being changed by new technologies, such as Intelligent Transportation Systems (ITS) which including smart cards, on-board diagnostics and information systems, and smarter highways, transit, automobiles, logistics systems, and other information systems [13]. The range of options and their impacts will continue to expand as new technologies are introduced over the next decades, and may alter transportation systems in many ways. Adoption of ICTs has a significant influence in public transport systems in term of the mobility of people and goods. ICTs are also a potentially important enabler of change in social and business organizational systems, thus affecting the demand for public transport in spatial and temporal terms. Technological trends will meet the demand for safety, speed and comfort through advances in ICT in the field of telematics. This covers systems for traffic and transport management, travel information and reservations, vehicle guidance, and mobility cards [14]. Over the last few years firms operating in the public transport sector have made significant progress in their adoption of new technologies, particularly those linked to the internet and e-business. Advanced traffic management systems could increase road capacity significantly while improving safety and respecting other objectives such as pedestrian comfort.

Over the longer run, automation could make order of magnitude improvements in safety, capacity, and convenience. To obtain the quality solutions needed in the organization and operation of public transport system, the use of interoperable ICT and Intelligent Transport Systems (ITS) in the transport should be encouraged further as a matter of priority [15].

A specific role for interoperability could be found in the exchange of information between agencies, operators and bus crews. Thus, means of transport synchronize their activities and the transported goods and passengers reach their destination on time and in full transparency of information. Smart technologies such radio frequency identification (RFID) should be introduced to contribute to improved efficiency and security, and provide new quality services for mobility of people and goods [16].

\section{Load Cells}

A load cell is a transducer that is used to convert a force into electrical signal. This is indirect conversion which occurs in two stages. Through a mechanical arrangement, the force being sensed deforms a strain gauge. Load Cells are used in several types of measuring instruments such as Laboratory Balances, Industrial and Commercial Scales, Platform Scales, and Weighbridges.

There are many configurations, but the most popular and the focus of our study is the Strain Gauge Load Cell (SGLC). Fig. 1 shows a typical example of SGLC, a double bending load cell element. The SGLC measures strain, and then transfers that force into electric energy which manifests as measurement for interpretation. Measuring strain effects helps preserve the integrity of the unit under pressure as well as protects equipment and people nearby [17].

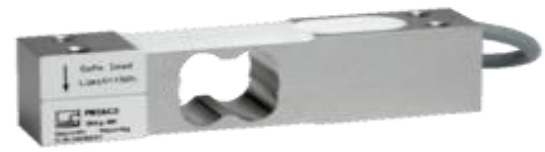

Fig. 1. Strain Gauge Load Cell [18]. 
SGLC are attached to structural bearing or support beam of an application that endures stresses and pressures, oftentimes with superglue or some other appropriate adhesive. When strain is put upon the bearing, the material's change in tension exerts force upon the SGLC, which sends an electrical signal through a switching unit. This signal manifests as a measurement of the load, and reveals how much tension is being placed upon the unit. Load cell display unit displays tension forces as well as temperature, voltage to frequency comparisons and other important information about the application. The measurement is calculated by a complex equation based on the reaction of four different measurements of stress and compression [18].

\section{Wireless Sensor Networks}

A Wireless Sensor Network (WSN) can be defined as a network of devices, denoted as nodes, which can cooperatively sense and may control the environment enabling interaction between persons or computers and the surrounding environment, and communicate the information gathered through wireless links [19]. The data is forwarded, possibly via multiple hops, to a sink (sometimes denoted as controller or monitor) that can use it locally or is connected to other networks (e.g., the Internet) through a gateway. The nodes can be stationary or moving; can be aware of their location or not; and can be homogeneous or not [20].

Fig. 2 shows a traditional Single-Sink (left part) and MultiSink (right part). Most of the scientific papers in the literature deal with such a definition. This single-sink scenario suffers from the lack of scalability: by increasing the number of nodes, the amount of data gathered by the sink increases and once its capacity is reached, the network size cannot be augmented. Moreover, for reasons related to Medium Access Control (MAC) and routing aspects, network performance cannot be considered independent from the network size [21].

\section{E. Cloud Technology [23]}

With the spread of broadband internet across the globe, more emphasis has been placed on how to effectively and efficiently utilize and allocate all the available computing, processing and storage capacity available globally. Resource sharing has enabled concepts such as Software as a Service, Platform as a Service and Database as a Service where the end user does not need to worry about the technical requirements of systems, software and the technical specifications of the database but just focuses on service usage. Cloud computing has made it possible for emerging companies to rollout their services at a much faster pace as the cost of data centres is slowly becoming a non-factor with cloud based solutions such as Data Centre as a Service (DCaaS). Cloud computing has brought about novel ideas where a computer is no longer viewed as a standalone entity but can span multiple hardware platforms and multiple geographical locations.

\section{F. Internet of Things}

Internet of Things (IoT) is defined as "the system of physical objects or things hooked up with hardware, software, sensors, and system connectivity which empowers these objects to gather and alternate information" [24]. IoT makes use of different kinds of protocols to work with exclusive objects [25].

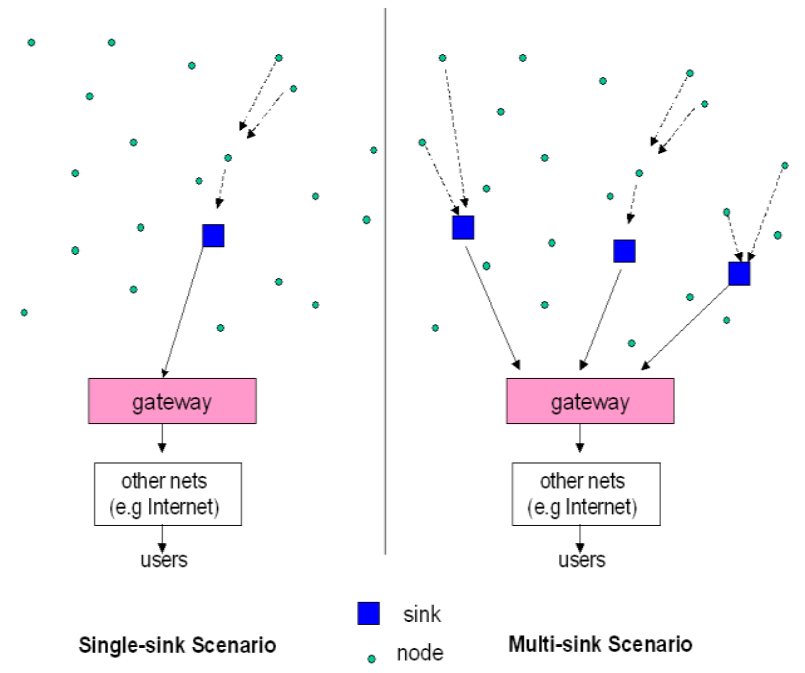

Fig. 2. Left Part: Single-Sink WSN. Right Part: Multi-Sink WSN [21] [22].

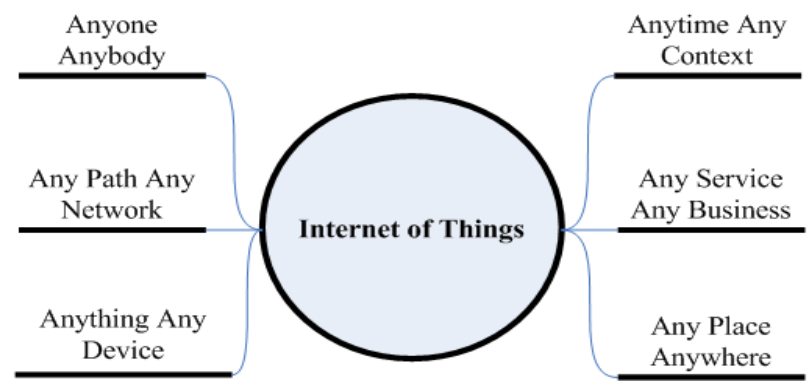

Fig. 3. IoT Definition/Concept [26] [27].

TABLE. I. IOT SMART APPLICATIONS AND SERVICES [27]

\begin{tabular}{|l|l|l|}
\hline No. & \multicolumn{3}{|l|}{ Application of Internet of things } \\
\hline & Service Domain & Services \\
\hline 1 & Smart Home & Entertainment, Internet Access \\
\hline 2 & Smart Office & $\begin{array}{l}\text { Secure File Exchange, Internet Access, } \\
\text { VPN, B2B }\end{array}$ \\
\hline 3 & Smart Retail & $\begin{array}{l}\text { Customer Privacy, Business } \\
\text { Transactions, Business Security, } \\
\text { Business Security, B2B, Sales \& } \\
\text { Logistics Management }\end{array}$ \\
\hline 4 & Smart City & $\begin{array}{l}\text { City Management, Resource } \\
\text { Management, Police Network, Fire } \\
\text { Department Network, Transportation } \\
\text { Management, Disaster Management }\end{array}$ \\
\hline 5 & Smart Agriculture & $\begin{array}{l}\text { Area Monitoring, Condition Sensing, } \\
\text { Fire Alarm, Trespassing }\end{array}$ \\
\hline 6 & $\begin{array}{l}\text { Smart Energy \& } \\
\text { Fuel }\end{array}$ & $\begin{array}{l}\text { Pipeline Monitoring, Tank Monitoring, } \\
\text { Power Line Monitoring, Trespassing \& } \\
\text { Damage Management }\end{array}$ \\
\hline 7 & $\begin{array}{l}\text { Smart } \\
\text { Transportation }\end{array}$ & $\begin{array}{l}\text { Road Condition Monitoring, Traffic Status } \\
\text { Monitoring, Navigation Support, Smart Car } \\
\text { support, Traffic Information Support, } \\
\text { Intelligent Transport System (ITS) }\end{array}$ \\
\hline
\end{tabular}


IoT also provides networking to connect people, things, applications, and data through the Internet to enable remote control, management, and interactive integrated services [28]. Fig. 3 and Table I shows a summary of the definition or concept of IoT and the numerous applications of IoT among others, respectively.

\section{G. Sensing Technology [29]}

Remote sensor networks have traditionally relied on four components, a sensor to collect the data, an aggregator to centralize the collection of data, an uplink network to relay the data and a server to which the data is to be sent. Wireless sensor network can be further broken down into two main components, the remote sensor network and the uplink. The remote sensor network is that part of the network that is composed of the sensors which have energy sources and some kind of personal area network used for localized communication. The network may also comprise a collaboration algorithm which may determine its work mode. The three main work modes that enable collaboration in a wireless sensor network are a star network, a mesh network or a ring network. The remote sensors basically sense, process and send the data either individually or through aggregator.

\section{Methodology}

The purpose of the baseline study was to establish the challenges by the public transport system with regard to management of load weight on buses. The method that guided this research was a Mixed Methods Research Methodology which comprises a combination of qualitative and quantitative research types. Descriptive statistics analysis technique was used to analyse the data obtained from the questionnaire. Qualitative data was analyzed by bringing out emerging themes that were categorized and interpreted to form part of the input in the design of proposed system. The use of filter questions in interviews was applied because not all and same questions were asked to the institutions/agencies, bus owners/operators and the bus crew. The use of filter questions is a common method in standardized questionnaire surveys to make the interview more effective and efficient.

This study was confined to Lusaka province of Zambia. It catered eleven (11) institutions/agencies with thirty-six (36) participants; fourteen (14) bus owners/operators; and fortytwo (42) bus crew; giving a population sample size of ninety two (92) participants. Non-probability sampling technique was used in this study because of the different specialized knowledge and work experience possessed in the subject area. This approach was preferred as the research required information from different stakeholders; those who were responsible for policy, regulation, enforcement, bus owners/operators, and the bus crew, who include drivers, conductors, inspectors, ticket sellers, and bus loaders. The age of the respondents who participated in this study ranged from 17 to 56 years old with $19.6 \%$ female and $80.4 \%$ male. The highest levels of education for the participants ranged from School Certificate to Master's degree. The current mode of load weight management on public buses in Zambia is as shown in Fig. 4.

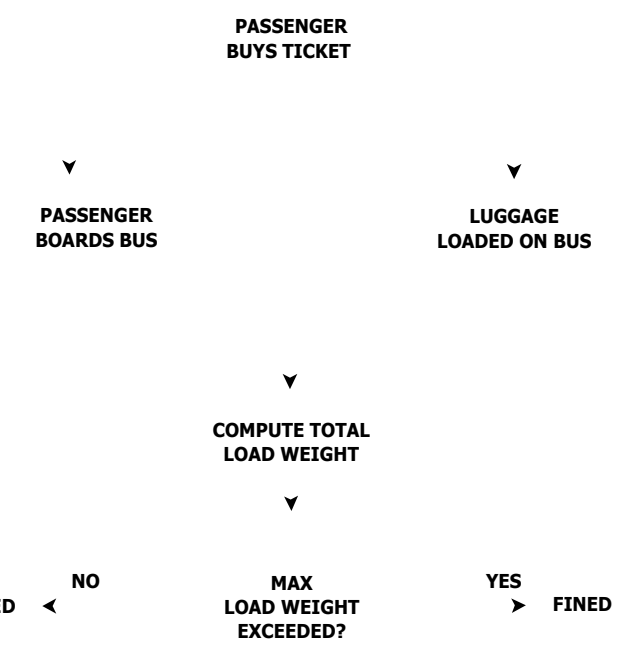

Fig. 4. Current Load Weight Management on Public Bus in Zambia.

\section{A. Proposed Load Weight Monitoring System}

Due to none existence of means to measure load weight on public buses, the need to come up with one motivated this study. Therefore, a Load Weight Monitoring System (LWMS) is proposed. The results of the baseline study were used to come up with a conceptual model and design for the LWMS on public buses as shown in Fig. 5.

The system development method used was the Water Fall Model approach and the qualitative data obtained from both the questionnaires and the interviews were used to come up with the system requirements. Currently, the bus seating capacity determines the limit and hence the number of tickets/passengers to loaded on the bus while there is no means to measure the weight of the luggage which is left to the discretion of the bus loaders and crew.

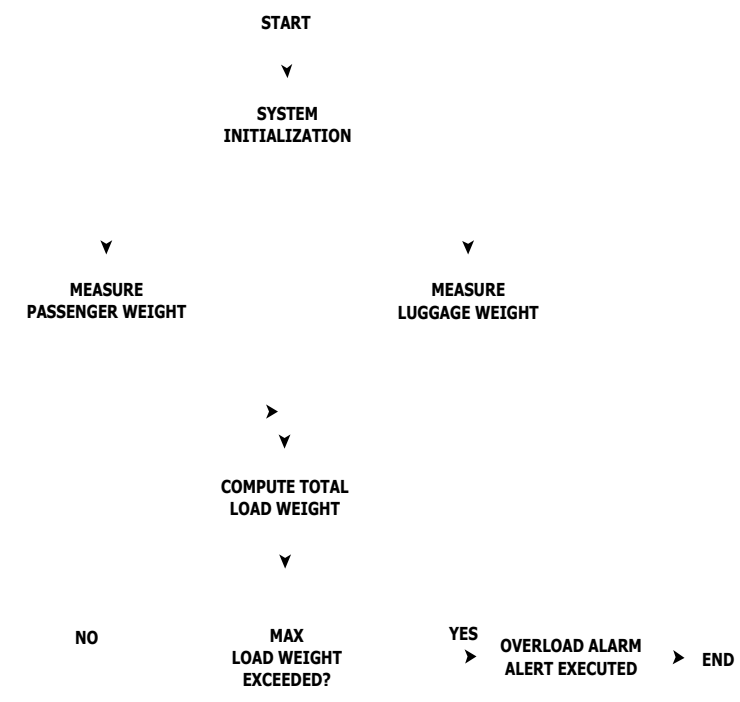

Fig. 5. Flowchart of Proposed LWMS Model. 


\section{B. System Design of LWMS}

The LWMS model was developed using of selected software and hardware materials suitable, to achieve the task at hand. Load Cells, Microcontrollers and Sensors were used to measure, monitor and control the weight of the load weight on the bus. A SIM900A GPRS/GSM Shield was used to provide GPRS services and connect to internet. This was essential to enable load weight data to be captured and logged in to the central database server for stored. This information which mainly consisted on the status of the load weight from the model was displayed using web pages created using HyperText Makeup Language (HTML), Cascading Style Sheets (CSS) and HyperText Preprocessor (PHP). Through the use of the GPRS/GSM service, the same information in form of Short Messaging System (SMS) was able to be sent to relevant agencies and/or owners/operators.

1) Load cell: A load cell is a transducer which converts force into a measurable electrical output. Load cell designs can be distinguished according to the type of output signal generated and the way the detect weight. They various types of load cells include: Hydraulic; Pneumatic; and Strain Gauge Load Cells. For details on load cell, refer to Literature Review in the previous section.

2) Arduino microcontroller: Arduino is an open-source electronics platform based on easy to use hardware and software. In its simplest form, an Arduino is a tiny computer that can be programmed to process inputs and outputs going to and from the chip. The Arduino is what is known as a Physical or Embedded Computing platform, which is an interactive system and through the use of hardware and software, it can interact with its environment. The main advantages of using an Arduino include following: Inexpensive; Cross-platform; Simple, Clear Programming Environment; Open Source and Extensible Software and Hardware.

3) SIM900A GPRS shield: The GPRS module is a breakout board and minimum system of SIM900A Quadband/SIM900A and Dual-band GSM/GPRS module. It is capable of communicating with controllers via ATtention (AT) commands which are instructions used to control a modem. These instructions help: Get information about the mobile phone; Get basic information about the subscriber; Get the current status of the mobile phone or GPRS/GSM module; Establish a data connection or voice connection to a remote modem; Send or delete an SMS message and obtain notifications of newly received SMS messages; Perform security related tasks such as changing a password; Control the presentation of error messages of AT commands; Get or changes the Configurations of a mobile phone or GPRS/GSM module; and Save the Configurations of a mobile phone or GPRS/GSM module. The module also furthermore supports software power on and reset functions.

4) Programming environment: Because the project include a web application to be developed, the use of HTML was essential. HTML which stands for Hypertext Makeup Language is a standard markup language for creating web pages and web applications. Through the use of HTML, CSS
(Cascading Style Sheet) and JavaScript was included to make the web application more dynamic and responsive.

PHP is a widely-used open source general-purpose scripting language that is especially suited for web development and can be embedded into HTML. What distinguishes PHP from other server-side scripting languages is that it is simple to use and code written can be executed on the server which then generates the required HTML pages. Further, more configuration of a webserver to process all HTML files using PHP is possible. For the purpose of this project, the latest version of PHP which was PHP 7.0 was used to create the web application necessary for the project.

Firebase is a mobile and web application development platform. It primarily consists of services such as: Firebase Clouding; Firebase Authentication; Real-time Database; and Firebase Hosting. An Arduino IDE platform was used to programme the microcontroller, sensors and shields used to develop the module. The Arduino IDE provided an easy interface to programme the different software programs required run the hardware devices of the model.

\section{System Implementation of LWMS}

The design of the LWMS model was split into two main separate modules for implementation purposes:

- LOADING BAY MODULE-represents the loading bay of luggage and is also concerned with measuring, monitoring and calculating the weight of luggage placed in the luggage compartment.

- STEP SENSOR MODULE-represents a step on the bus and is also concern with measuring, monitoring and calculating the weight of passengers and hand luggage in and out of the bus.

The main technique used in the design was Process Modelling and used the flowcharts for clarity and easy of description of the logic for the entire model. Fig. 5 shows the flowchart for the proposed LWMS model.

1) Loading bay: Fig. 6 below shows the flow of the proposed Loading Bay module for the LWMS model. The Loading Bay module was used to measure, monitor and calculate the weight of luggage either in or out of the luggage compartment of the bus. A threshold was set to indicate the maximum allowed luggage weight loaded on the bus. Main components of the Loading Bay module were: Arduino Uno Microcontroller; Load Cell; Liquid Crystal Display (LCD); and Piezo Buzzer.

2) Step and motion sensors: Fig. 7 shows the flow chart for the proposed Step Sensor module for LWMS model. The Step Sensor initialization occurs when the system boots, thereafter it remains idle and waits for any motion to be detected. Once motion is detected, code in the Step Sensor determines whether it was a forward motion, that is, a passenger steps into the bus or backward motion, that is, a passenger steps out of the bus. Depending on the type of motion, the load value on the local storage of the Step Sensor, the Arduino storage is updated with a new value for the load weight of the vehicle, this value is then transferred to the 
online database. It is the value in the database that the system checks to ensure the vehicle is not exceeding the allowed maximum load weight.

The Step Sensor is crucial in detecting passenger weight and it consists of the following components: Motion Sensors, a GSM module and load cell, all of which are linked through an Arduino Uno Microcontroller development board.

Fig. 8 illustrates diagrammatically the set-up of the Step and Motion Sensors. The Side view shows how the sensors are positioned one after the other, in relation to the position of the load cell while the Top view shows the sideward position of the Sensors in order to detect the forward or backward motion direction. The bus entrance has one of the steps embedded with a load cell under it.

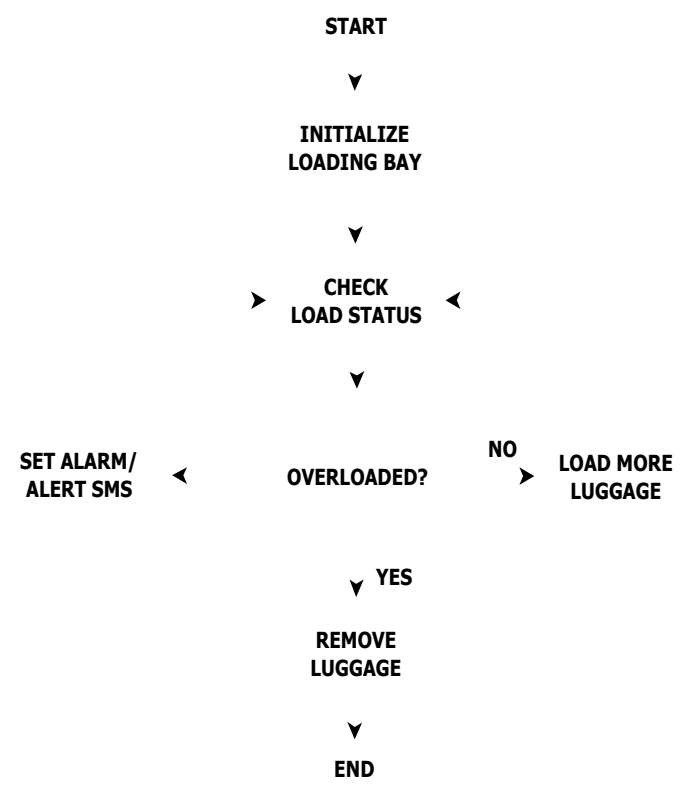

Fig. 6. Flowchart of Proposed Loading Bay.

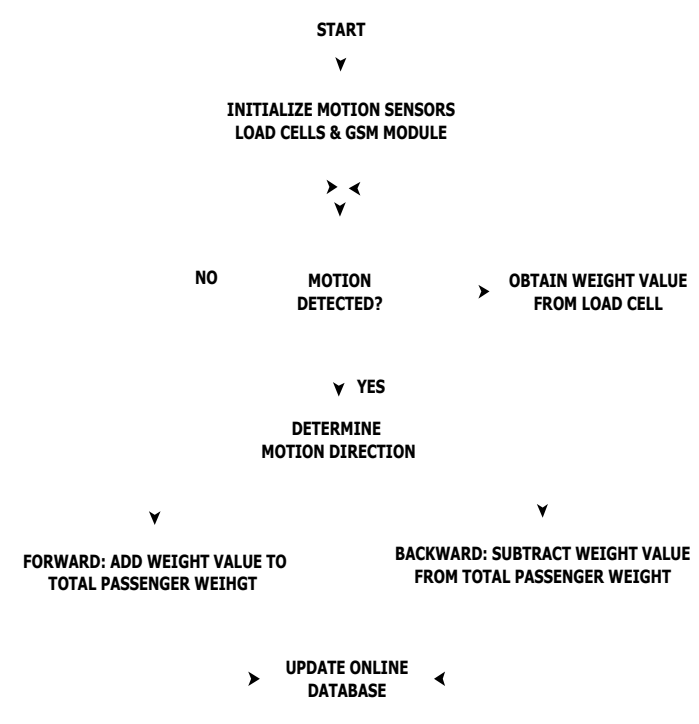

Fig. 7. Flowchart of Proposed Step/Motion Sensor.

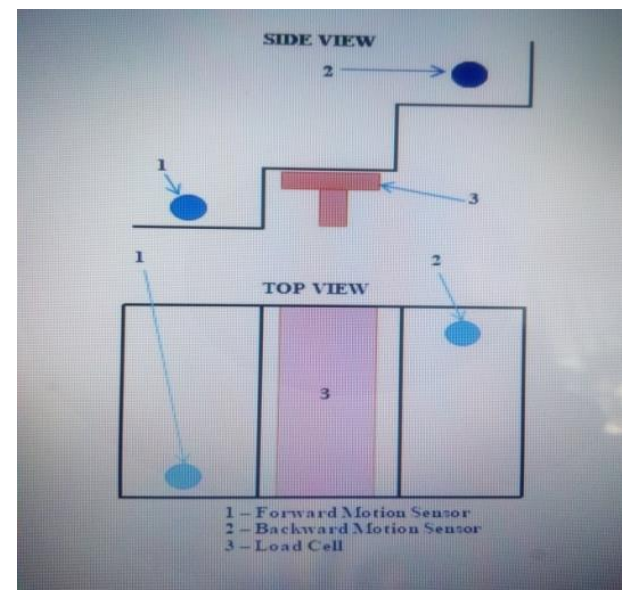

Fig. 8. Step- Motion Sensors Design.

The HC-SR501 Passive Infra-Red (PIR) Motion Sensors is compatible with an Arduino Uno Microcontroller. It possess a 110 degrees viewing area, range of 3 to 7 meters, a LHI778 Infrared Sensor that detects light, and a BISS0001 Integrated Circuit which controls how motion is detected.

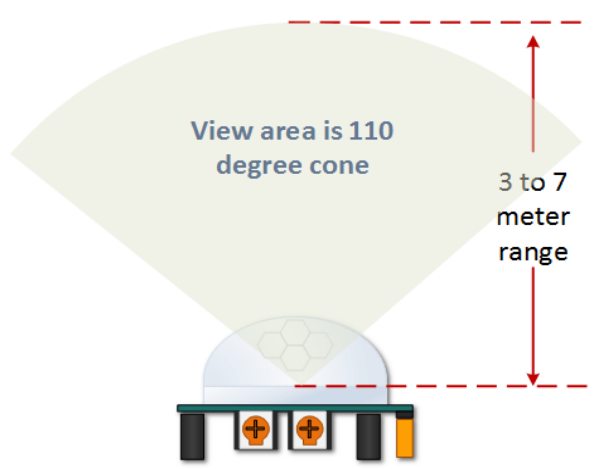

Fig. 9. HC-SR5O1 Field of View and Range [25].

The HC-SR501's field of view is enhanced by the presence of a spherical Fresnel cap which reflects light inwards towards the infrared sensor [30] as shown in Fig. 9 above. The positioning of the motion sensors is very important; one sensor is placed in front of the other in the step sensor. This is designed in this way so that the order in which the motion sensors are triggered determines the direction of motion of the step and subsequently whether to add or subtract the value of the weight that is detected by the load cell placed underneath the step. Fig. 10 below is the layout of the $\mathrm{HC}$ SR501 motion sensor.

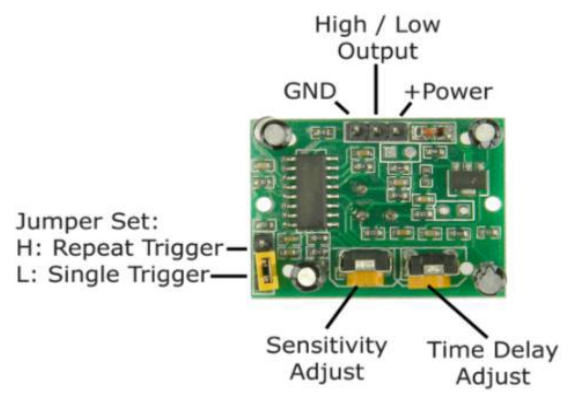

Fig. 10. Layout of HC-SR501 PIR Motion Sensor. 
3) GSM module: The LWMS model updates the online centralized database through the use of wireless digital communication link, the GSM module. The specification of module used in the model is the TinySine GSM shield which uses the SIM900 module. It can be used to send and receive data, voice calls and SMS messages, hence its suitability for the model. However the speed of the device is slow, which is a great hindrance to updating the database. This makes the use of the Arduino and GSM module inappropriate for commercial deployment of the proposed system but is adequate for demonstration purposes. When the maximum load weight of the bus is exceeded the GSM module sends an SMS to the bus owner/operator and relevant agencies.

\section{RESULTS}

The main focus of the study was to appreciate the challenge of passengers and luggage overloading on public buses and then propose a solution, the LWMS, to mitigate overloading.

\section{A. Baseline Study}

The results of the baseline study are presented as derived from the analysis of the questionnaire. All key stakeholders confirmed that there was rampant overloading on public buses because of none availability of means to measure luggage and passengers at the bus stations. The research findings confirm that the challenge of overloading, as indicated in Table II, was attributed mainly to luggage at 93 percent while that of passengers was only about 7 percent.

Another interesting revelation from the study was the varying perception from various stakeholders on the most risk factors contributing to road traffic accidents (RTAs) as shown in Table III.

Worth noting is also the overall responses from all stakeholders on the most risk factor that contributes to RTAs as being the human factor at 54 percent compared to the next road/environmental factors at 39 percent as shown in Fig. 11 below. Further analysis of human factors, revealed issues of over speeding, driver fatigue, substance use or drunk driving and use of cell phone while driving. However, there was no direct mention of overloading as a cause of RTA, though acknowledged to rampant and a road safety hazard. Indirect mention of tyre burst as a cause of RTA due to overloading was mentioned.

\section{B. System Implementation of LWMS}

The LWMS prototype model was implemented successfully and it was capable of performing the required tasks as specified. The separation of the Loading Bay and Step Sensor modules was done to facilitate easy in design and implementation, and clarity in explanation.

1) Loading bay module: Fig. 12 below shows the fully implemented Loading Bay module for the LWMS. The main components include: No.1: Weighing Platform-surface upon which the luggage is placed for measurement; No.2: Load Cell-active component transducer that converts physical weight into electric signals; and No.3 Base Mounting-firm base that holds and supports the entire device.

2) Step sensor module: Fig. 13 shows the fully implemented Step Sensor module for the LWMS. The main components include: No.1: Motion Sensors-shielded to avoid wrong motion detection; No.2: Step Sensor-imbedded with a Load Cell; No.3: Arduino/GSM-module for control and communication; and No. 4: Breadboard-used to inter connections.

TABLE. II. CHALLENGE OF OVERLOADING ON BUSES

\begin{tabular}{|l|l|l|l|}
\hline & CAUSE & NUMBER & PERCENT \\
\hline 1 & Luggage & 86 & $\mathbf{9 3 . 4}$ \\
\hline 2 & Passengers & 06 & $\mathbf{6 . 6}$ \\
\hline 3 & TOTAL & 92 & $\mathbf{1 0 0}$ \\
\hline
\end{tabular}

TABLE. III. MOST RISK FACTOR CONTRIBUTING TO RTAS

\begin{tabular}{|l|l|l|l|l|l|}
\hline & $\begin{array}{l}\text { FACTOR } \\
\text { S }\end{array}$ & $\begin{array}{l}\text { INSTITUTION } \\
\text { S }\end{array}$ & $\begin{array}{l}\text { OWNER } \\
\text { S }\end{array}$ & $\begin{array}{l}\text { CRE } \\
\text { W }\end{array}$ & $\begin{array}{l}\text { OVERAL } \\
\text { L }\end{array}$ \\
\hline 1 & Human & $75 \%$ & $29 \%$ & $35 \%$ & $\mathbf{5 4 \%}$ \\
\hline 2 & Road/En & $19 \%$ & $64 \%$ & $55 \%$ & $\mathbf{3 9 \%}$ \\
\hline 3 & Vehicle & $03 \%$ & $07 \%$ & $10 \%$ & $\mathbf{0 6 \%}$ \\
\hline 4 & Others & $03 \%$ & $00 \%$ & $00 \%$ & $\mathbf{0 1 \%}$ \\
\hline 5 & TOTAL & $100 \%$ & $100 \%$ & $100 \%$ & $\mathbf{1 0 0 \%}$ \\
\hline
\end{tabular}

RTA FACTORS - OVERALL
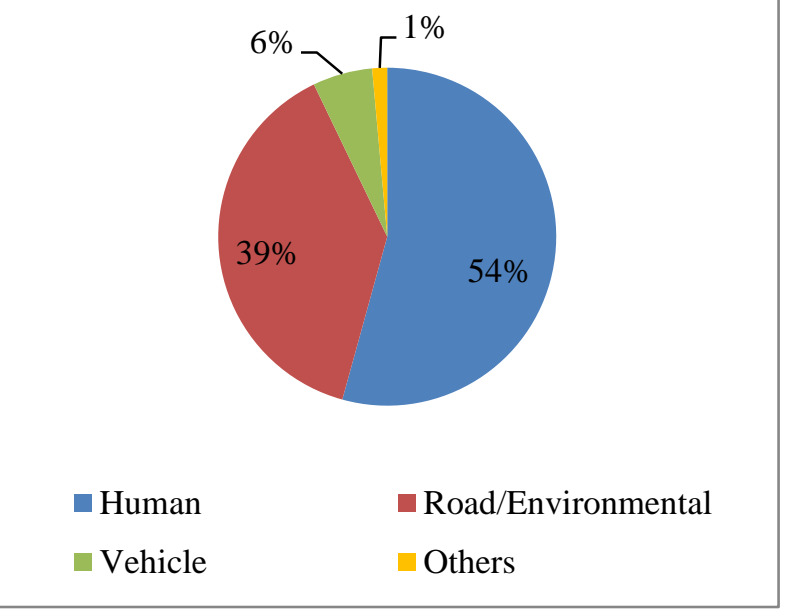

Fig. 11. Factors of RTA-Overall Perception.

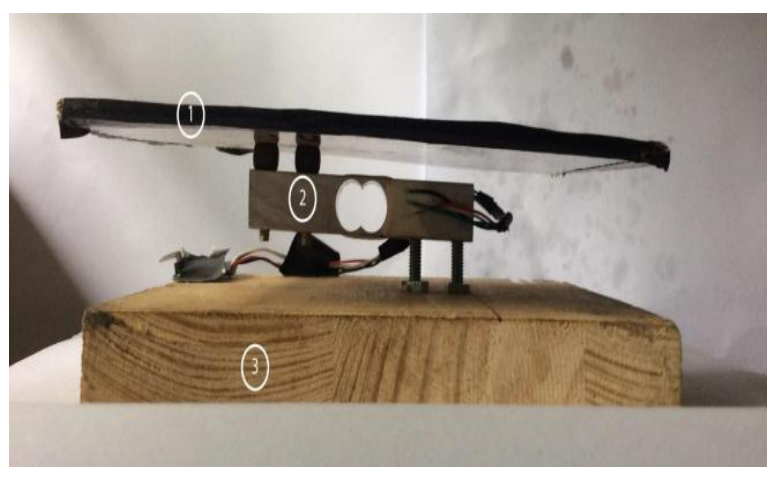

Fig. 12. Loading Bay for the LWMS. 


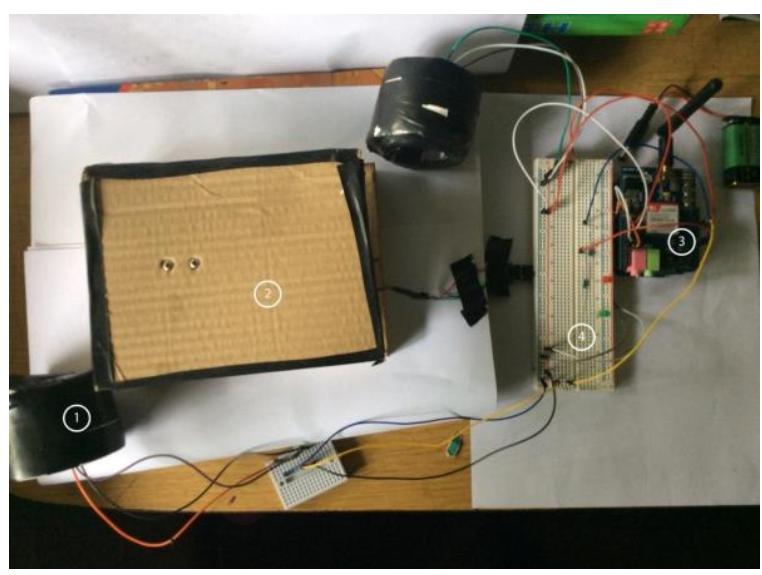

Fig. 13. Step Sensor Component for the LWMS

3) Web application and mobile app: This module provides the user interface to enable the user to monitor the current load weight of the bus as the passengers and luggage are loaded, using the Software Component of the system. It was essential for users of the system to have real time information displaying the current status of load weight of the bus at any given time. This is achieved through use of a thin client model in a browser. A user of the system is able to login to the system, using his/her credentials and check the status of the bus through a browser. use of a browser is not very efficient as it is not real time, so the client is able to access his/her bus status through a mobile application. Fig. 14 shows the screenshot of the user's view of the current weight calculated from the prototype model.

The client can view the current weight of the bus through the browser as shown above. Upon reading the Loading Bay and Step values, they are added and then data was sent to online database through the GSM module already described above. The process of transmitting data was successful with the only drawback of the slow speed at which the Arduino uploaded the data. When the maximum load weight is exceed, an overload alert alarm is excited and an SMS message is sent to the bus owner/operator and relevant agencies using the GSM module which is equipped with a SIM card to connect to Mobile Network Service Provider to report overloading. Fig. 15 shows the screenshot the alert message.

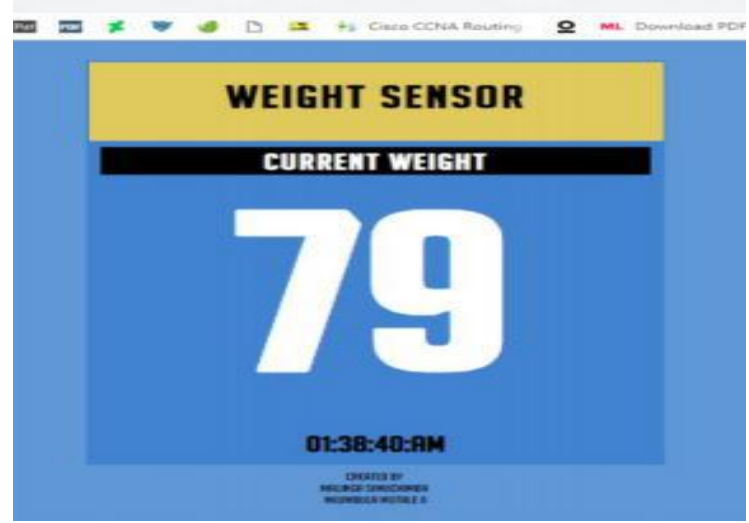

Fig. 14. User View of the Current Weight.

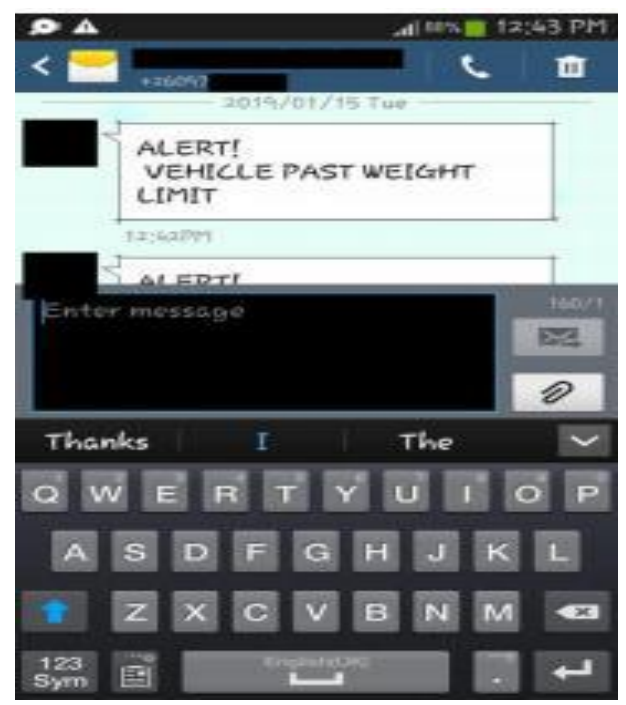

Fig. 15. Screenshot_2019-01-15-12-43-27.

\section{DISCUSSION}

The objectives of the research study were realized; conduct baseline study, propose and design new system, and develop prototype model of new system. A baseline study was conducted in order to establish the challenge of overloading on public buses in Zambia to which all stakeholders positively affirmed its existence and also affirmed need to have an automatic load weight monitoring system to prevent overloading. From results of analysis of the respondents' feedback, it was overwhelming that overloading was real, attributed to over loading of luggage and passengers. While there was currently no mean to measure the weights of both luggage and passengers, the latter was relatively easy to handle because it is limited by the seating capacity of the bus. Accordingly, the number of tickets sold corresponds to the bus seating capacity thereby limiting number of passengers boarding the bus, hence rarely contribute to overloading. On the other hand, the former in current situation is very difficult to manage in establishing the weight of luggage loaded on each bus because apart from passenger luggage, there is also additional unaccompanied luggage carried on the bus for extra income for the crew without the knowledge of the owners/operators.

The baseline findings helped to come up with a solution that is perceived to be much better so as to solve the challenge of overloading on public buses using modern technology to improve efficiency in operation, road safety, reduce infrastructure and vehicle degradation, and many more.

\section{CONCLUSION}

This research study brought out important points on the fact that the challenge of overloading on public buses in Zambia is related to one of the factors that contribute to road traffic accidents, that is, the human factor. Further analysis of human factors revealed that a number of issues ranging from social-economic factors to survival requirements contribute to the crew overload the buses to make extra income without the knowledge of the bus owners/operators and contravening road traffic regulations. 
The proposed LWMS would introduce an orderly, logical and accountable system with up-to-date accurate data on the load weight of each bus at any given time using the state-ofart technology. A major contribution of this paper is in explaining the challenge of overloading on public buses which helped to come up with a solution that uses the current technologies to ensure efficiency and road safety in the public road transport system. Many other sectors of the road transport system can also take advantage of the emerging technologies to ensure compliance of maximum load weight limit at the source, for example, at the quarry the trucks carrying construction materials can be weighed at the source also to prevent overloading of the trucks. The results obtained show that in Zambia, there is already a wide use of these ICTs like digital communication system of Public Mobile Network which was easily integrated to be used for data transmission to all other relevant parties. Other ICT infrastructure already in use like the Transport Intelligent System (TIS) and Vehicle Identification (VID) may be easily integrated with the LWMS.

As technology keeps on changing and advancing, it is important that the management and operation of public transport system in Zambia is kept abreast with the world trends like tighter coordination between all agencies in the sector by sharing computer infrastructure resources cloud computing, centralized databases, and so on. The phenomenon of overloading on public buses is multi-sectorial in nature and hence requires consented effort from all stakeholders to combat. These efforts may require policy, legal, social, institutional and infrastructural reforms. As a way forward, employing technology in the management of load weight on buses could be well integrated with other initiatives like the intelligent road management systems. The introduction of Global Positioning System (GPS) on some public buses to monitor speed in dealing with the challenge of over-speeding can also in a similar way be made to incorporate overloading. The use of Weight-In-Motion (WIM) technology in the management load weight of commercial vehicles on the roads as done in developed countries need to be thoroughly studied so that it can also be incorporated in our systems too.

Future works for this prototype model would see it develop to be a full-fledged bus system, one to be used for ticketing of passengers. The addition of a full-fledged user Mobile application would lend to this idea, passengers would be able to book a ticket and also make payments through it. Adding RFID for use with the luggage tracking would improve the security of the system too. Future editions of the system would seek to use better communication technology, possibly through the use of a Wi-Fi module to improve on the speed at which the $\mathrm{w}$ values of the weights are uploaded. Furthermore, clients of the system, i.e. bus owners should be given more functionality through a Client App. The option to intervene when the bus is overloaded would be of great benefit, for instance, the option to disable the bus through the app would go a long ways to preventing road infrastructure damage and all other associated risks. Additionally, power to the client would be in form of GPS functionality to the Client App., the ability to monitor the position, speed, and so on of the bus would be an added benefit for the system versatility.
On the overall, the anticipated benefits and associated cost savings of LWMS to reduced overloading relates to operational enhancements, road infrastructure preservation, increased road safety, reduced vehicle damage, congestion, fuel consumption and reduced harmful emissions.

It is recommended that strong collaboration exists between all relevant stakeholders to combat overloading. It is also recommended that this proposal be extended to other heavy commercial vehicles (HCV) with modification to establish load weight at the source, e.g., construction vehicles from the quarry sites, trucks from industrial loading bays, and so on.

\section{ACKNOWLEDGMENT}

We are grateful to the various institutions/agencies ZMA, ZABS, RTSA, NRFA, RDA, ZACL, ZAMPOST, LIBT, ZCILT, BTOAZ, PPDAZ; bus owners/operators, and some all bus crew of LIBT for allowing us to carry out this research and for positive responses, and for providing us with valuable data in pursuit of proposing an automated system of monitoring load weight.

\section{REFERENCES}

[1] Laudon, K. C., and Laudon, J. P., "Management Information Systems Managing the Digital Firm", 13th Global ed., Harlow, Essex: Pearson Education Limited, 2014.

[2] Milumbe, B., Phiri, J., Kalumbilo M.M., Nyirenda, M., "Developing a Candidate Registration System for Zambia School Examinations using the Cloud Model", International Journal of Advanced Computer Science Applications (IJACSA), Vol. 9, No.7, 2018, pp. 38.

[3] Richard IIes, "Problems and Characteristics of Public Transport in Developing Countries"Emerald Group Publishing Limited,2005,pp.5-37.

[4] Hashim, W., Kami, 1. A. and Mustaffa, M., 2012. "An Overview of Heavy Vehicles Safety Related to Speed and Mass Limit in Malaysia". Mara, UiTM.

[5] Zambia, Laws of Zambia. Public Roads Act No. 12 of 2002, Lusaka, Lusaka: Zambian Parliament, 2002.

[6] Nordengen, P. A. and Naidoo, O. J., 2014. "Evaluation of the Road Transport Management System, a self-regulation initiative in heavy vehicle transport in South Africa”. Transport Research Arena, pp. 2-3.

[7] Karim, M. R., Ibrahim, N. I., Saifizul, A. A. and Yamanaka, H., 2014. "Effectiveness of Vehicle Weight Enforcement in a Developing Country using Weigh-in-Motion Sorting System considering Vehicle By-pass and Enforcement Capability". International Association of Traffic and Safety Science Research (IATSSR), Issue 37, p. 124-129.

[8] Zambia, Laws of Zambia. Metrology Act No. 6 of 2017. Lusaka, Lusaka: Zambian Parliament, 2017.

[9] Zambia, Laws of Zambia. Roads and Road Traffic Act of Zambia, Chapter 464, Part XIV, Sub-Article 245. Lusaka, Lusaka: Zambian Parliament, 1995.

[10] Russo, F., and Comi, A., "Measurements in Freight Transportation", Journal of Urban Planning and Development, June 2011, Vol. 137, No. 2, pp. 142-152.

[11] Lucey, T., Management Information Systems, 9th edition, London: BookPower, 2005.

[12] Avram Olaru, M.G., "Advantages and challenges of adopting cloud computing from an enterprise perspective", Procedia Technology, vol. 12, pp. 529-534, 2014.

[13] Lawrence E. Decina et al., 2007, "Automated Enforcement: A Compendium of Worldwide Evaluations of Results", U.S. Department of Transportation, National Highway Traffic Safety Administration, Report No. DOT HS 810 763, Washington, DC.

[14] Nolan, P., Zhang, J. and Liu, C., "The global business revolution, the Cascade Effect, and the Challenge for Firms from Developing Countries", Cambridge Journal of Economics, Vol. 32, No. 1, 2011, pp. 29-47. 
[15] Hamilton, A., Waterson, B., Cherrett, T., Robinson, A. and Snell, I. "The Evolution of Urban Transport: Changing Policy and Technology", Transportation Planning and Technology, Vol. 36 No. 1, pp. 24-43, 2013.

[16] Kittelson and Associates, et al., 2007, TCRP Report 118: Bus Rapid Transit Practitioner's Guide, National Academies Transportation Research Board, U.S. Federal Transit Administration, Washington, DC.

[17] Ghanvat S.M., Patil H.G., "Shape Optimization of S-Type Load Cell using Finite Element Method" International Journal of Engineering Innovation and Research (IJEIR), Vol. 1, Issue 3, ISSN:2277-5668, 2012.

[18] James F. Doyle, J.F., and Phillips,J.W., "Manual on Experimental Stress Analysis", Society for Experimental Mechanics, 2010.

[19] Tubaishat M., Madria S., Wireless Sensor Networks: An Overview. IEEE Potentials. 2003; 22:20-30.

[20] Verdone, R., Dardari, D., Mazzini, G., Conti, A., "Wireless Sensor and Actuator Networks". Elsevier; London, UK: 2008.

[21] IEEE 802.15.4 Standard, Part 15.4: Wireless Medium Access Control (MAC) and Physical Layer (PHY) Specifications for Low-Rate Wireless Personal Area Networks (LR-WPANs) IEEE; Piscataway, NJ, USA: 2006.

[22] IEEE Standard 802.15.4, 2015, Revised IEEE Standard 802.15.4 2011, "IEEE Standard for Low-Rate Wireless Networks", pp. 1-709, Apr. 2016.

[23] Muyunda, T., Phiri, J., "A Web based Inventory Control System using Cloud Architecture and Barcode Technology for Zambia Air Force",
International Journal of Advanced Computer Science and Applications (IJACSA), Vol. 8, No. 11, 2017, pp. 134.

[24] Chihana, S., Phiri, J. and Kunda, D., "An IoT based Warehouse Intrusion Detection (E-Perimeter) and Grain Tracking Model for Food Reserve Agency", International Journal of Advanced Computer Science and Applications (IJACSA), Vol. 9, No. 9, 2018, pp. 214.

[25] Laxmirajam, E. C., and Kawitkar, D.R.S., "A Survey: IoT based Vehicle Tracking System," International Journal of Advanced Research in Computer and Communication Engineering, Vol. 6, No. 5, pp. 791795, 2017.

[26] Choudhari, S., Rasal, T., Suryawanshi, S., Mane, M., and Yedge, P.S., "Survey Paper on Internet of Things: IoT", International Journal of Engineering Science and Computing, Vol. 7, No. 4, pp. 10564-10567, 2017.

[27] Bandyopadhyay, D., and Sen, J., "Internet of Things - Applications and Challenges in Technology and Standardization", Wireless Perscommum, 2011.

[28] Phiri, H. and Phiri, J., "Real Time Sensing and Monitoring of Environmental Conditions in a Chicken House", ResearchGate, Conference Paper -May 2018.

[29] Mulima, C., Phiri, J., “A Remote Sensor Network using Android Things and Cloud Computing for the Food Reserve Agency in Zambia." International Journal of Advanced Computer Science and Applications (IJACSA), Vol. 8, No. 11, 2017, pp. 412.

[30] Caussignac J.M., Rougier J.C., "Fibre Optic WIM Sensor and Optoelectronic System-Preliminary Tests", Hermes Science Publications, Paris, 1999. 